\title{
ANALYSIS OF CONVECTIONAL HEAT TRANSFER OF AG- MGO \\ (WATER BASE) HYBRID NANOFLUID OVER STRETCHING
}

\author{
SHEET WITH MHD \\ R. VASANTHAKUMARI ${ }^{1} \&$ PRAGYA $^{2}$ \\ ${ }^{I}$ Associate Professor, Kanchi Mamunivar Centre for Postgraduate Studies, Pondicherry, India \\ ${ }^{2}$ Research scholar, Department of Mathematics, Bharathiar University, Coimbatore, Tamil Nadu, India
}

\begin{abstract}
The steady two dimensional laminar, boundary layer flow of incompressible, viscous hybrid Nano -fluid over a stretching sheet with MHD is studied. Water is taken as the base fluid and volume fraction of nanoparticle is considered between 0 to $0.06(50 \%$ of silver and 50\% magnesium oxide). PDE is transformed into ODE. The solution of equations is obtained from MATLAB using bvp4c. Various physical parameters such as Reynold's number, Nusselt number, skin friction coefficient are calculated. It was found that hybrid Nanofluid has better heat transfer capacity than single nanoparticle (silver) fluid.

KEYWORDS: Hybrid Nanofluids, Stretching Sheet, MATLAB \& MHD
\end{abstract}

Received: Jun 02, 2018; Accepted: Jun 22, 2018; Published: Jul 16, 2018; Paper Id.: IJMPERDAUG201857

\section{INTRODUCTION}

Nanofluids have brought the great revolution in the field of cooling process of instruments. They were first discovered by Choi [1]. Fluids showed tremendous enhancement in thermophysical properties when small Nanosized particles were suspended in base fluid. Some commonly used based fluids are Water, ethylene whereas Nanoparticles may be metals ( $\mathrm{Al}, \mathrm{Cu}, \mathrm{Ag}, \mathrm{Au}, \mathrm{Fe}$ ), their oxides (Al2O3, $\mathrm{CuO}, \mathrm{TiO} 2)$, their carbide, $(\mathrm{SiC})$, Nitride (AlN, SiN) or even non-metals (graphite carbon nanotubes). Due to their highly efficient cooling property, Nanofluids have gained tremendous importance in almost all fields. Nanofluids are used for cooling in industries, vehicle cooling, cooling of medical instruments etc. It was found that by dispersing 1-5\% Nanofluids in the base fluid, thermal conductivity increases by $150 \%$.

Boundary layer flow is studied widely due to their large area of practical importance. Boundary layer flow was discovered by Prandtl. Boundary layer problem along stretching sheet has attracted the attention of many researchers due to its practical applicability. Stretching sheet is used in many industrial processes like drawing continuous filament and fiber spinning, glass fiber production, extrusion of polymer and many more. During the process of manufacturing these sheets, metal is stretched to achieve a desired thickness. The quality of final product is determined by the rate of cooling and stretching rate. This can be done by using an electrically conducting fluids and applying MHD. Buogiorno [3] explained the significant increase in thermal conductivity. Khan and Pop [10] discussed boundary layer flow of Nano fluids over a stretching sheet and investigated it numerically. 
Nanofluids emerged as the solution for a heating problem. There are many investigations regarding the use of Nanofluid in conventional heat transfer method. [21-26] It tackled heating issues of fluids in a more efficient way than base fluid. But, the need for better fluid for cooling still persist. Hybrid Nanofluids catered the need of the situation. Many practical experiments are done on hybrid Nanofluids in recent years. It was observed that among all hybrid Nanofluids, $\mathrm{Ag}$ and $\mathrm{Al}_{2} \mathrm{O}_{3}$ / water is most effective coolant. They showed a significant increase in heat transfer coefficient. $\mathrm{Ag}$ and $\mathrm{MgO} /$ water hybrid Nanofluid with volume fraction between 0- 2\% was analysed by Hemmat et al. [19]. Moghadassi et al [20] numerically studied about $\mathrm{Cu}-\mathrm{Al} 2 \mathrm{O} 3$ /water in a horizontal circular tube. The nusselt number showed a significant increase. Nuim Labib et.al. [7] Numerically solved problem of forced convection on hybrid Nanofluid. Mixed convection along inclined tube with hybrid Nanofluid was analysed by Momin [11]. Suresh et.al. Studied [12] role of Cu- Al2O3 /water in heat transfer.

In present study our aim is to study effect of $\mathrm{Ag}-\mathrm{MgO} /$ water (50\% of silver and $50 \%$ magnesium oxide) Nanofluid with MHD along linear stretching sheet. Partial Differential Equations are converted to Ordinary Differential Equations. Then these equations are solved with MATLAB software. Graphical result is demonstrated for various physical parameters.

\section{Nomenclature}

Cp: Specific heat

$\beta$ : Thermal expansion coefficient

$\mathrm{T}$ : temperature

$\mathrm{k}$ : thermal conductivity

$\mathrm{Nu}$ : local Nusselt number

Re: Reynold's number

$\alpha$ : thermal diffusibility

$\beta$ : thermal expansion coefficient

ф: solid volume fraction

$\theta$ : dimensionless temperature

$\eta$ : similarity variable

f: fluids

nf: nanofluids

s: solid particles

$\mu$ :dynamic viscosity

$\mathrm{B}_{0}$ : Magnetic field 


\section{MATHEMATICAL MODELING}

A two -dimensional steady, laminar, incompressible and electronically conducting Ag-MgO/water is passed over a hot linear stretching plate. The x-axis is assumed to coincide with the direction of sheet and y-axis is taken as the direction perpendicular to the sheet. A uniform magnetic field is of strength B0 is applied along Y axis. . The velocity of the stretching sheet is given by equation $\mathrm{u}=\mathrm{ax}$ where a are positive and is considered as constant acceleration parameter. Taking Prandtl boundary layer equations based on principle of conservation of mass, energy and momentum, reducing equations in 2D for hybrid Nanofluids we get following set of equations:

$$
\begin{aligned}
& \frac{\partial u}{\partial x}+\frac{\partial v}{\partial y}=0 \\
& u \frac{\partial u}{\partial x}+v \frac{\partial u}{\partial y}=\vartheta_{n f} \frac{\partial^{2} u}{\partial y^{2}}+\frac{\sigma B_{0}^{2} u}{\rho_{n f}} \\
& u \frac{\partial T}{\partial x}+v \frac{\partial T}{\partial y}=\alpha_{n f} \frac{\partial^{2} T}{\partial y^{2}}
\end{aligned}
$$

Along with boundary conditions for velocity and temperature:

$$
\begin{aligned}
& y=0, u=u_{w}, v=0, T=T_{w}+\mathrm{ax} \\
& y \rightarrow \infty, u \rightarrow 0, T \rightarrow T_{\infty}
\end{aligned}
$$

Where $\mathrm{u}$ and $\mathrm{v}$ are components of velocity along $\mathrm{x}$ and y directions respectively, $\mathrm{T}$ is temperature, $\boldsymbol{\vartheta}_{\boldsymbol{n} \boldsymbol{f}}$ is kinematic viscosity of Nanofluids, $\boldsymbol{\alpha}_{\boldsymbol{n} \boldsymbol{f}}$ is thermal infusibility of Nanofluids, $\mathrm{k}_{\mathrm{nf}}$ thermal conductivity, $(\mathrm{C} \mathrm{p})_{\mathrm{nf}}$ is specific heat, $\mathrm{B}_{0}$ is applied magnetic field and $\rho_{\mathrm{nf}}$ density of hybrid Nanofluids.

Along with boundary condition:

$$
\begin{aligned}
& \mathrm{y}=0, \mathrm{u}=\operatorname{Uw}(\mathrm{x})=\mathrm{ax} \\
& y \rightarrow \infty, u \rightarrow 0, T \rightarrow T_{\infty}
\end{aligned}
$$

The, density, specific heat and heat capacitance of hybrid nanofluid:

$$
\begin{aligned}
& \left.\left.\rho_{n f=\left\{( 1 - \emptyset _ { 2 } ) \left[\left(1-\emptyset_{1}\right) \rho_{f}\right.\right.}+\emptyset_{1} \rho_{s 1}\right]\right\}+\phi_{2} s_{2} \\
& \left.\left.\left(\rho C_{p}\right)_{n f=\left\{( 1 - \emptyset _ { 2 } ) \left[\left(1-\emptyset_{1}\left(\rho C_{p}\right)_{f}\right.\right.\right.}+\emptyset_{1}\left(\rho C_{p}\right)_{s 1}\right]\right\}+\emptyset_{2}\left(\rho C_{p}\right)_{s 2}
\end{aligned}
$$

The dynamic viscosity of hybrid nanofluid as formulated by Brickman :

$\mu=\frac{\mu_{f}}{\left(1-\emptyset_{1}\right)^{2.5}\left(1-\emptyset_{2}\right)^{2.5}}$

Table 1: Physical Properties of Base Fluid Water, Silver, Titanium Oxide

\begin{tabular}{|l|c|c|c|}
\hline & $\mathbf{( ~ k g ~ / ~ m 3 ) ~}$ & $\mathbf{C p}$ ( J/ kg. K) & K ( W / m. K ) \\
\hline Water & 997.1 & 4179 & 0.613 \\
\hline Silver & 10,500 & 234 & 429 \\
\hline Magnesium oxide & 3,560 & 955 & 45 \\
\hline
\end{tabular}

P. D. E are converted into ODE using similarity variable $\eta$.

$\psi=\left(a \vartheta_{n f}\right)^{1 / 2} x f(\eta)$ 
$\eta=\left(\frac{a}{\vartheta_{n f}}\right)^{1 / 2} y$

$u=\operatorname{ax} f^{\prime}(\eta)$

$v=-\left(a \vartheta_{n f}\right)^{\frac{1}{2}} f(\eta)$

Where $\boldsymbol{\Psi}(\mathrm{x}, \mathrm{y})$ is stream function and $u=\frac{\partial \psi}{\partial y}$ and $v=-\frac{\partial \psi}{\partial x}$,

and,$\theta(\eta)=\frac{T-T_{\infty}}{T_{w}-T_{\infty}}$

Equations (2) and (3) are transformed into ordinary differential equation given below:

$f^{\prime \prime \prime}=\left(\left\{\left(1-\emptyset_{2}\right)\left[\left(1-\emptyset_{1}\right) \rho_{f}+\emptyset_{1} \rho_{s 1}\right]+\emptyset_{2} \rho_{s 1}\right\}+\emptyset_{2} \frac{\rho_{s 2}}{\rho_{f}}\right)\left(f^{\prime 2}-f f^{\prime \prime}\right)-M^{2} f^{\prime}$

$\theta^{\prime \prime}=-\left(\frac{K_{f}}{k_{n f}}\right)\left\{\left(1-\emptyset_{2}\right)\left[\left(1-\emptyset_{1}\right)+\emptyset_{1} \frac{\left(\rho C_{p)_{s 1}}\right.}{\left(\rho C_{p)_{f}}\right.}\right]+\emptyset_{2} \frac{\left(\rho C_{p)_{s 2}}\right.}{\left(\rho C_{p)_{f}}\right.}\right\} \operatorname{Pr} f \theta^{\prime}$

Where $M^{2}=\frac{\sigma B_{0}^{2}}{a \rho_{f}}$

Along with boundary conditions:

$\eta=0, \mathrm{y}=0, \mathrm{f}=0, \mathrm{f}=1, \theta=1$

$\eta \rightarrow \infty, y \rightarrow \infty, f^{\prime}=0, \theta=0$

The variables are defined as

$\operatorname{Pr}_{n f}=\frac{\vartheta_{n f}}{\alpha_{n f}}$

Kinematic viscosity and thermal diffusivity of the hybrid nanofluids are respectively:

$\vartheta_{n f}=\frac{\mu_{n f}}{\rho_{n f}}$

and

$\alpha_{n f}=\frac{k_{n f}}{\rho_{n f\left(C_{p}\right)_{n f}}}$

And thus $(\operatorname{Pr})_{\mathrm{nf}}$, the Prandtl number of hybrid nanofluid

$P r_{n f}=\mu_{n f} \frac{\left(C_{p}\right)_{n f}}{k_{n f}}$

\section{Skin Friction Coefficient}

The skin friction coefficient $c_{f}$ is given by $C_{f}=\frac{\tau_{w}}{\rho_{f} U_{w}^{2}}$, where $\tau_{w}=\mu_{n f}\left(\frac{\partial u}{\partial y)_{y=0}}\right.$. Using (9), we get $C_{f} R e_{x}^{1 / 2}=\frac{1}{(1-\emptyset)^{2.5}} f^{\prime \prime}(0)$. 


\section{Nusselt Number}

Nusselt number is defined by: $N u=\frac{x q_{w}}{k_{f}\left(T_{w}-T_{f}\right)} \quad$ Where $\quad q_{w}=-k_{n f}\left(\frac{\partial T}{\partial y}\right)_{y=0}$. Using $\quad(9) \quad$ we $\quad$ get $N u R e_{x}^{-1 / 2}=-\frac{k_{n f}}{K_{f}} \theta^{\prime}(0)$

\section{Solution of the Equations}

Equations 13 and 14 were solved using boundary conditions 15 using MATLAB software with bvp4c. Equations 13 and 14 were converted into five equations each of first order. The value of $\eta$ was calculated at each iteration loop by $\eta_{\mathrm{n}+1}=\eta_{\mathrm{n}}+\Delta \eta$. The step size $\Delta \eta=0.001$ was used. The numerical solution with $\eta_{\max }=10$ was obtained and the six decimal place was considered as a criterion for convergence. Graphs were plotted for results obtained.

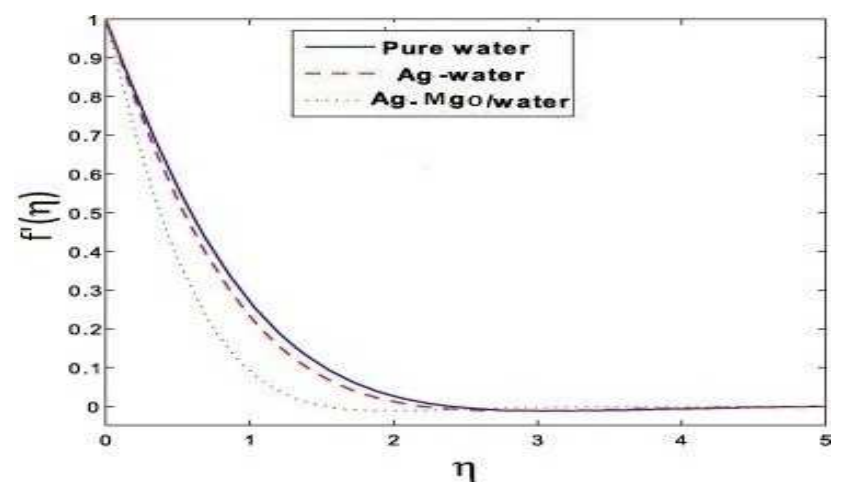

Graph 1

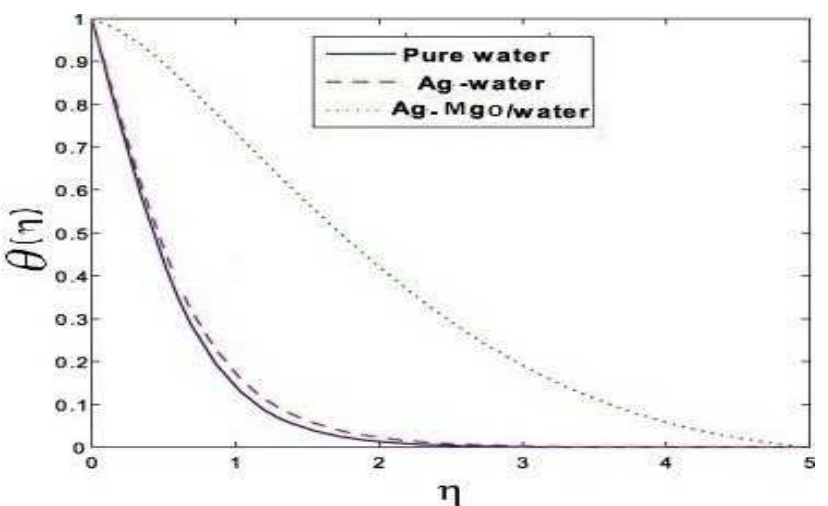

Graph 2

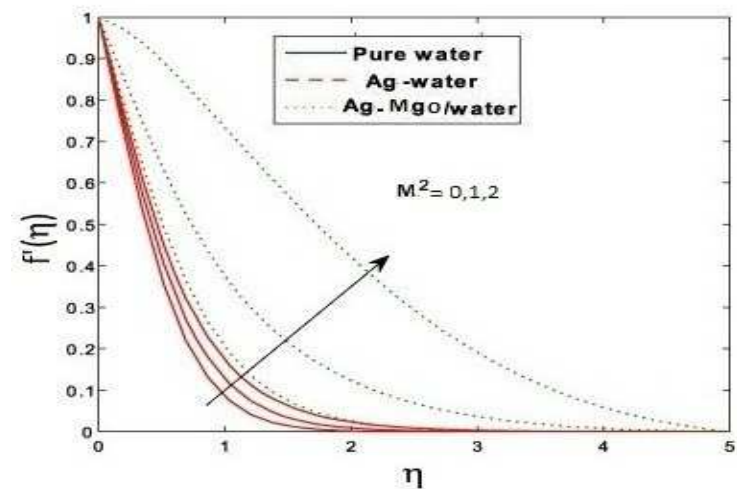

Graph 3 


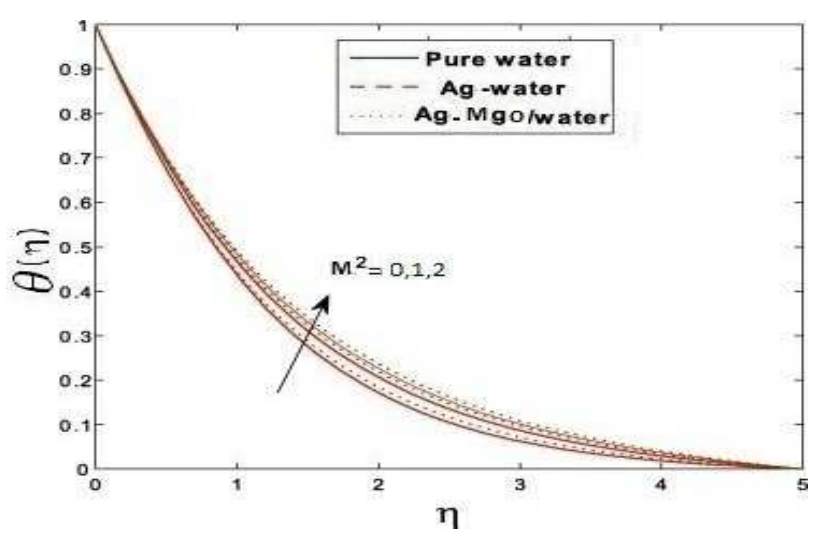

Graph 4

\section{RESULTS AND DISCUSSIONS}

Laminar flow of hybrid nanofluid over a stretching sheet is studied. Solutions for equations depicting thermophysical properties of both hybrid as well as plane $(\mathrm{Ag})$ nanofluids is obtained.

In absence of nanoparticles results shows excellent agreement with previous studies. Prandtl number is taken as 6.2. By taking values of $\emptyset_{1}=0$ and $\emptyset_{2}=0$ the results shows an excellent agreement with previous study.

It was observed that the velocity of the fluid decreases by adding nanoparticles. Hybrid nanofluid further retards velocity as the concentration of nanoparticles increases Temperature also drops significantly by adding nanoparticles . Nanoparticles exert energy in form of the heat. Hybrid nanofluid further drops the temperature. M was taken as 2.

Graph 3 shows an effect of the magnetic parameter over dimensionless velocity for nanofluids. Due to magnetic field Lorentz force is induced which results in decrease of velocity i.e. increase in magnetic field results in the decrease in velocity. Hybrid nanofluid further retards the velocity. Effect of magnetic field on temperature profile is depicted in Graph 4. This figure shows that by increasing value of magnetic field increases temperature. Thermal boundary layer thickness increases due to increase in magnetic field. Further hybrid nanofluid produces a better result by increasing MHD.

\section{REFERENCES}

1. S Choi, J A Eastman: "Enhancing thermal conductivity of fluids with Nano particles", ASME International mechanical Engineering congress and exposition conference, 1995 pp. 105-109.

2. Das S. K., Putra N, Theisen P, Roetzel W: "Temperature dependence of thermal conductivity enhancement for Nano fluids," Journal of heat transfer, 2003, pp. 567-579

3. Buongiorno J., “Convective transfer in Nano fluids, ” ASME J. Heat Transfer, vol. 128, pp. 240-250, 2006.

4. Ang, X. Q. \& Mujumdar, A. S., "Heat transfer characteristics of Nano fluids: A review Internal. Journal of Thermal Sciences, vol.46, pp.1-19, 2007.

5. Ahmad S. and Pop I., "Mixed convection boundary layer flow from a vertical plate embedded in a porous medium filled with Nano fluids.” International Communications in Heat and Mass Transfer, vol. 37, pp. 987-991, 2010.

6. $\quad$ Pitchandi, K. "Analysis of biomass based downdraft gasifier using equilibrium model." IJME 1 (2012): 26-34

7. Makinde O. D. and Aziz A., "Boundary layer flow of Nano fluid past a stretching sheet with convective boundary condition, "International Journal of Thermal Sciences, vol. 50, no. 7, pp. 1326-1332, July 2011 
8. Labib M. N., Nine M. J., Afrianto H., Chung H., Jeong H." Numerical investigation on effect of base fluids and hybridnanofluid in forced convective heat transfer". International Journal of Thermal Science 2013; 71: 163-71.

9. Vajravelu K., Prasad K. V., Lee J., Lee C. Pop I. and Van Gorder R. A., "Convective heat transfer in the flow of viscous Agwater and Cu-water Nano fluids over a stretching surface," International Journal of Thermal Science, vol. 50, pp. 843-851, 2011.

10. N. F. M. Noor, S. Abbas bandy and I. Hashim, "Heat and mass transfer of thermophore tic MHD flow over an inclined radiate isothermal permeable surface in the presence of heat source/sink, "International Journal of Heat and Mass Transfer, vol. 55, pp. 2122-2128, 2012.

11. W. A. Khan, I. Pop.," Boundary-layer flow of a nanofluid past a stretching sheet." International Journal of Heat and Mass Transfer 53 (2010) 2477-2483

12. Gaffar G. Momin. ," Experimental investigation of mixed convection with water Al2O3 and hybrid nanofluid in inclined tube for laminar flow”'. International Journal of Scientific \& Technology Research, 2:195-202, 2013.

13. S. Suresh, K. P. Venkitaraj, P. Selvakumar, and M. Chandrasekar," Effect of Al2O3 - Cu/water hybrid nanofluid in heat transfer", Experimental Thermal and Fluid Science, 38:54 - 60, 2012.

14. Sudhakar, S., and G. Mohan kumar. "To compare the effects of static stretching and eccentric training on hamstring flexibility in collegiate male athletes."

15. O. D. Makinde, W. A. Khan and Z. H. Khan, "Buoyancy effects on MHD stagnation point flow and heat transfer of a Nano fluid past a convectively heated stretching/shrinking sheet," International Journal of Heat Mass Transfer, vol. 62, pp. 526533, 2013.

16. O. D. Makinde, "Computational modelling of Nano fluids flow over a convectively heated unsteady stretching sheet," Current Nanoscience, vol. 9, pp. 673-678, 2013.

17. S. Das, R. N. Jana and O. D. Makinde, "MHD Boundary layer slip flow and heat transfer of Nano fluid past a vertical stretching sheet with non-uniform heat generation/absorption, ”International Journal of Nano sciences, vol. 13, 2014.

18. Mohsen Sheikholeslami, Davood Domiri Ganji, M. Younus Javed and R. Ellahi, "Effect of thermal radiation on magneto hydrodynamics Nano fluid flow and heat transfer by means of two phase model," Journal of Magnetism and Magnetic Material , vol. 374, pp. 36-43, 2015.

19. S. Nadeem, Rashid Mehmood and Noreen Sher Akbar, "Partial slip effect on non-aligned stagnation point Nano fluid over a stretching convective surface," Chinese Physics B, vol. 24, no. 1, 2015.

20. S. Nadeem, R. Mehmood and S. S. Motsab, “Numerical investigation on MHD oblique flow of a Walter's B type Nano fluid over a convective surface,” International Journal of Thermal Science, vol. 92, no. C, pp. 162-172, 2015

21. Esfe MH, Arani AA, Rezaie M, Yan WM, Karimipour A. , "Experimental determination of thermal conductivity and dynamic viscosity of Ag- MgO/water hybrid Nano fluid “,. International Communications in Heat and Mass Transfer. 2015 Aug 31; 66:189-95

22. Rajalaxmi, V., G. Mohankumar, And K. Ramanathan. "Effectiveness Of Plantar Fascia Stretching Vs Contrast Bath Combined With Ultrasound In Plantar Fasciitis."

23. Moghadassi A, Ghomi E, Parvizian F." A numerical study of water based Al2O3 and Al2O3-Cu hybrid Nano fluid effect on forced convective heat transfer", International Journal of Thermal Sciences. 2015 Jun 30; 92:50-7. 
24. Sheikholeslami M, Hatami M, Ganji DD.," Micro polar fluid flow and heat transfer in a permeable channel using analytical method",. Journal of Molecular Liquids. 2014 Jun 30; 194:30-6.

25. Bourantas GC, Loukopoulos VC.," MHD natural convection flow in an inclined square enclosure filled with a micropolarnanofluid”, International Journal of Heat and Mass Transfer. 2014 Dec 31; 79:930-44.

26. Turkyilmazoglu M.," A note on micro polar fluid flow and heat transfer over a porous shrinking sheet", International Journal of Heat and Mass Transfer. 2014 May 31; 72:388-91.

27. Jena SK, Malla LK, Mahapatra SK, Chamkha AJ.," Transient buoyancy-opposed double diffusive convection of micro polar fluids in a square enclosure”, International Journal of Heat and Mass Transfer. 2015 Feb 28; 81:681-94.

28. Fakour M, Vahabzadeh A, Ganji DD, Hatami M.," Analytical study of micro polar fluid flow and heat transfer in a channel with permeable walls"'. Journal of Molecular Liquids. 2015 Apr 30; 204:198-204.

29. Borelli A, Giantesses G, Patria MC," Magnetoconvection of a micropolar fluid in a vertical channel", International Journal of Heat and Mass Transfer. 2015 Jan 31; 80:614-25. 